\title{
Pityriasis Lichenoides et Varioliformis Acuta: Case Report and Review of the Literature
}

\author{
Neide Pereira $^{\mathrm{a}} \quad$ Ana Brinca $^{\mathrm{a}} \quad$ Maria Manuel Brites $^{\mathrm{a}}$ \\ Maria José Julião ${ }^{b} \quad$ Oscar Tellechea $^{a} \quad$ Margarida Gonçalo $^{a}$ \\ Departments of ${ }^{\mathrm{a}}$ Dermatology and ${ }^{\mathrm{b}}$ Pathology, Coimbra University Hospital, \\ Coimbra, Portugal
}

\section{Key Words}

Pityriasis lichenoides et varioliformis acuta - Erythromycin - Methylprednisolone

\begin{abstract}
We report a case of a 63-year-old man hospitalized for a polymorphous generalized eruption consisting of maculopapules with peripheral scaling, vesicopustules, and ulceronecrotic and crusted lesions measuring 5-20 mm, localized on his trunk and extremities, particularly exuberant in the flexural area. Histopathology showed necrotic keratinocytes with exocytosis of red blood cells and lymphocytes and a dermal perivascular and periadnexal inflammatory infiltrate, composed of CD8+/CD4-/CD30- T cells, indicating the clinical diagnosis of pityriasis lichenoides et varioliformis acuta. He was treated with erythromycin and methylprednisolone reduced gradually over 5 months, with a slow but complete response; the patient was without lesions after 2 years of follow-up. The authors want to remind of this rare entity which may present difficulties in diagnosis and therapy.
\end{abstract}

\section{Introduction}

Pityriasis lichenoides (PL), an uncommon dermatitis, previously included in the parapsoriasis group, may appear in two clinical forms: the acute variant also known as pityriasis lichenoides et varioliformis acuta (PLEVA); and the chronic variant or pityriasis lichenoides chronica (PLC) [1].

The etiology of PLEVA remains unknown. Several hypotheses have been proposed to explain this dermatitis: an inflammatory reaction triggered by infectious agents, an 
inflammatory response secondary to T-cell dyscrasia, or an immune complex-mediated hypersensitivity [2].

\section{Case Report}

A 63-year-old previously healthy man gradually developed, over 2 weeks, a widespread polymorphous and generalized eruption with papular and ulcerohemorrhagic skin lesions associated in the last days with fever, malaise, and myalgia that prompted his admittance to our department. His personal and family histories were non-contributory. He denied taking any medications and there was no apparent episode of any infection before the onset of the eruption.

Physical skin examination revealed confluent erythematous and/or purpuric macules, papules, plaques with peripheral scaling, vesicopustules, and ulceronecrotic lesions with hemorrhagic crusts (fig. 1). Lesions in different evolutionary stages varying in size from 5 to $20 \mathrm{~mm}$ were observed on the trunk and extremities, including palms and soles, and were particularly exuberant in the flexural, neck, and genital area (fig. 2). Face and mucous membranes were spared. The patient had a slight fever $\left(38^{\circ} \mathrm{C}\right)$ and reported malaise and myalgia only on the first day of hospitalization. Pruritus was modest. No adenopathies or other objective signs were detected during the physical examination.

Laboratory findings included full blood cell count with differential, liver, and renal studies, serum protein electrophoresis, immunoglobulins, C3, C4, and antinuclear antibodies; serology for hepatitis B virus, hepatitis C virus, HIV, Epstein-Barr virus, cytomegalovirus, herpes simplex virus and Toxoplasmosis as well as Treponema pallidum were normal or negative. Direct immunofluorescence for HSV or VZV and viral cultures from the vesicles taken on the day of admission as well as bacterial skin cultures were negative.

Histopathology showed mild acanthosis, vacuolization of the basal layer with necrotic keratinocytes and exocytosis of red blood cells and lymphocytes, and a dermal perivascular and periadnexal lymphocytic infiltrate with no atypia (fig. 3). On immunohistochemistry staining, infiltrating cells were mostly positive for CD8 and negative for CD4 and CD30, therefore indicating the diagnosis of PLEVA with a predominance of CD8 cells without CD30 cells, in which case lymphomatoid papulosis was less likely.

Oral erythromycin (1 g per day), topical corticosteroids, and antihistamines were prescribed, but because of an insufficient clinical response after 2 weeks, oral methylprednisolone ( $32 \mathrm{mg} /$ day) was added. Erythromycin was given for 3 months, and the systemic steroids were tapered gradually over 5 months, with residual macular pigmented lesions still persisting at the end of this treatment. Regular clinical and laboratorial follow-up for the next 2 years showed no recurrence of skin lesions or any other systemic alteration.

\section{Discussion}

It is generally accepted that PLEVA and PLC represent two ends of a continuous spectrum, and therefore it is not uncommon to observe both acute and chronic lesions in the same patient, as well as lesions at intermediate stages between PLEVA and PLC [3].

PLEVA is characterized by erythematous macules that quickly evolve into papules with a fine micaceous scale. As the scale thickens, it often becomes free at the periphery but remains attached centrally. The papule often has a central punctum that becomes vesiculopustular, undergoes hemorrhagic necrosis, and becomes ulcerated, with overlying red-brown crusts. Varioliform scars and postinflammatory hyper- and hypopigmentation may result. Symptoms include burning and pruritus. PLEVA most often occurs on the trunk, extremities, and flexural areas, but diffuse and generalized 
patterns may also occur. The eruption is polymorphous, as lesions exist in all stages of development, and successive crops of lesions can last indefinitely, from a few weeks to months or years [4].

The differential diagnosis for PLEVA includes lymphomatoid papulosis (the condition most commonly mistaken for PLEVA), arthropod bite reactions, varicella, Gianotti-Crosti syndrome, erythema multiforme, pityriasis rosea, guttate psoriasis, vasculitis, and secondary syphilis [1].

The relationship of pityriasis lichenoides to lymphomatoid papulosis remains controversial. Differentiation between these two conditions is, however, important because patients with lymphomatoid papulosis, unlike those with pityriasis lichenoides, may develop systemic lymphoma [5]. The presence of large CD30+ atypical lymphoid cells is the hallmark of lymphomatoid papulosis [6]. Other differences include the presence of large, atypical, non-lymphoid cells that may resemble Reed-Sternberg cells, many neutrophils, few lymphocytes, few or no necrotic keratinocytes, and little or no vacuolar degeneration of the basal layer, observed in lymphomatoid papulosis as opposed to PLEVA [5]. Clinically, the papules of lymphomatoid papulosis may develop into nodules, tumors, and large plaques (unlike PLEVA). The cutaneous eruption tends to last much longer than that of PLEVA, sometimes even for years [1].

Clinical management of PL is difficult due to its uncertain etiology. Since the disease tends towards self-resolution, evaluation of treatments without adequate controls cannot result in useful recommendations. Case reports suggest the use of multiple oral medications including tetracycline [7], erythromycin [8], methotrexate, calciferol, chinoline and acridine derivates, cyclosporine, intravenous gamma globulin, and retinoids [1]. Systemic corticosteroids may have a role in severe cases of PLEVA. Topical corticosteroids and antihistamines are helpful in symptomatic cases, but they do not alter the course of the disease. Recently, good responses with topical tacrolimus treatment were reported [9]. Current knowledge about the efficacy of phototherapy for PL is limited and is mostly based on anecdotal reports and small-scale studies [10].

Despite a lack of randomized controlled trials, oral tetracycline and erythromycin have been prescribed most often in case series.

In conclusion, the authors want to remind of this rare entity which may present difficulties in diagnosis and therapy. Exocytosis of T cells, with a CD8+/CD30phenotype, favors the diagnosis of PLEVA and excludes lymphomatoid papulosis. Macrolid and steroid was effective in this patient, even though one cannot exclude the possibility of a spontaneous resolution.

\section{Disclosure Statement}

The authors declare that they have no conflict of interest. 


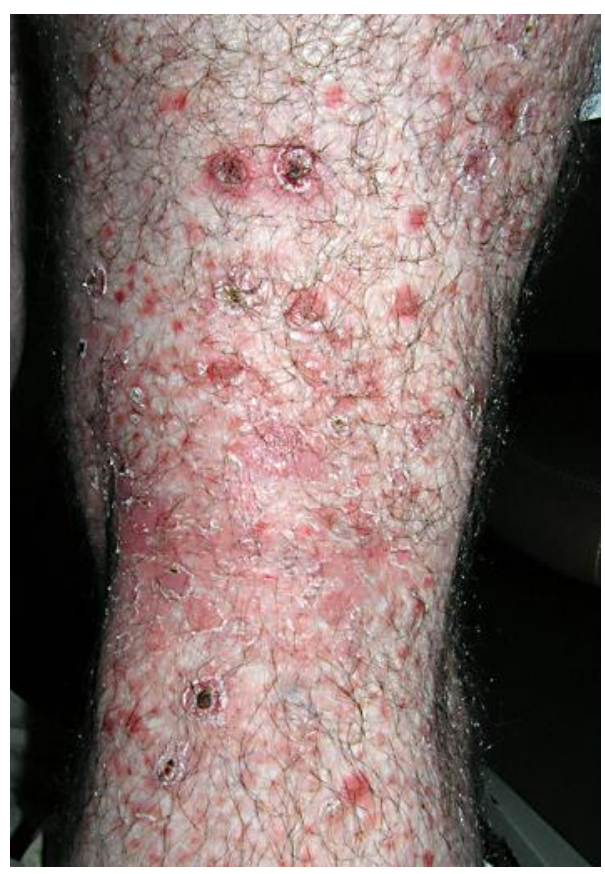

Fig. 1. Ulceronecrotic lesions with hemorrhagic crusts varying from 5 to $20 \mathrm{~mm}$ in diameter.

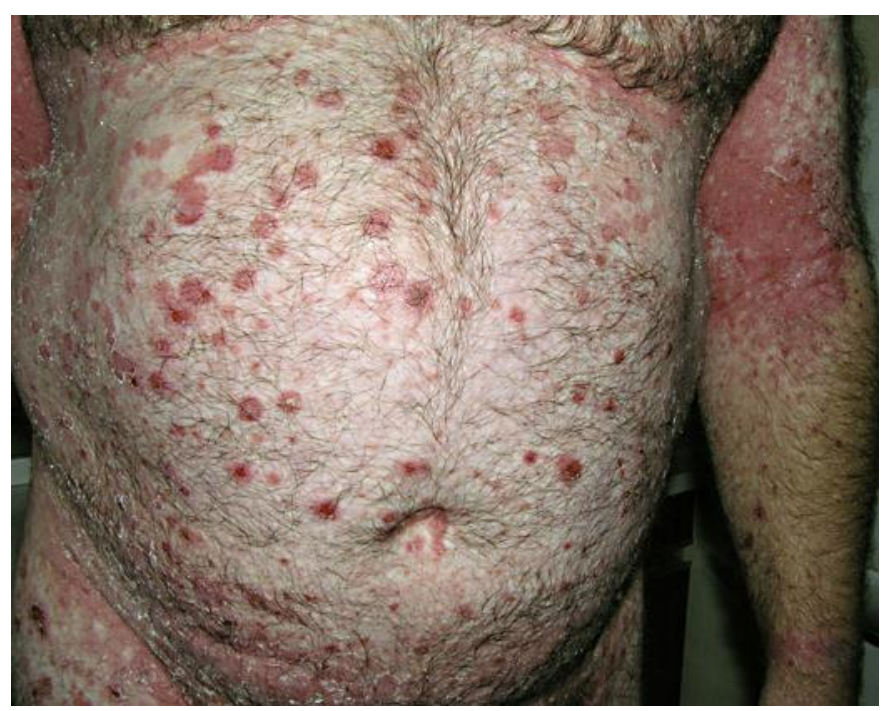

Fig. 2. Polymorphous clinical appearance of early lesions. 


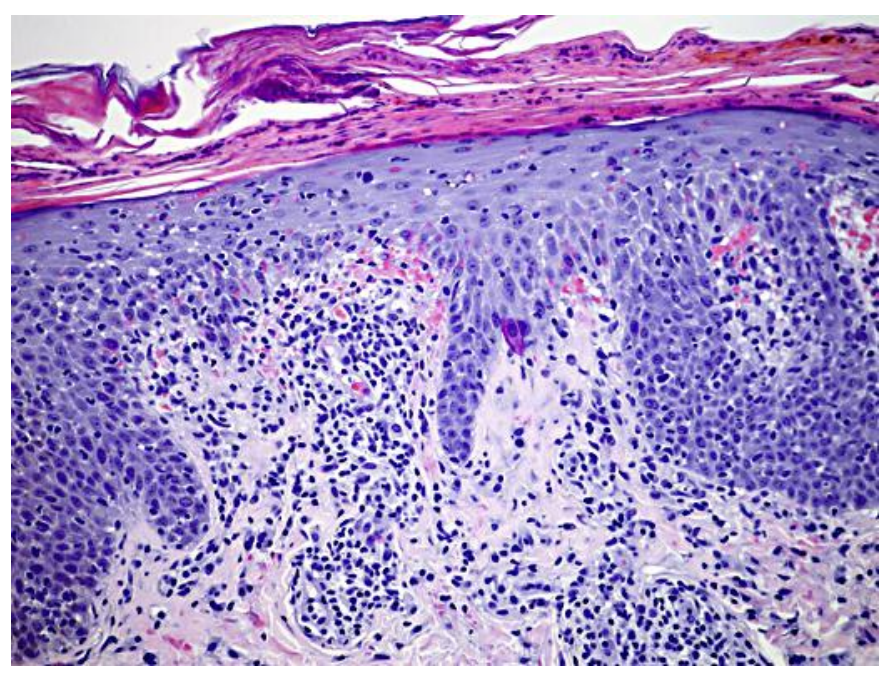

Fig. 3. Histopathology showing mild acanthosis, vacuolization of the basal layer with necrotic keratinocytes and exocytosis of red blood cells and lymphocytes. In the dermis, a lymphocytic perivascular and periadnexal inflammatory infiltrate can be observed. The infiltrating cells showed no atypia. $\mathrm{HE}, \times 100$.

\section{References}

1 Bowers S, Warshaw EM: Pityriasis lichenoides and its subtypes. J Am Acad Dermatol 2006;55:557-572.

-2 Fernandes NF, Rozdeba PJ, Schwartz RA, Kihiczak G, Lambert WC: Pityriasis lichenoides et varioliformis acuta: a disease spectrum. Int J Dermatol 2010;49:257-261.

-3 Ersoy-Evans S, Greco MF, Mancini AJ, et al: Pityriasis lichenoides in childhood: a retrospective review of 124 patients. J Am Acad Dermatol 2007;56:205-210.

$\checkmark 4$ Hood AF, Mark EJ: Histopathologic diagnosis of pityriasis lichenoides et varioliformis acuta and its clinical correlation. Arch Dermatol 1982;118:478-482.

5 Willemze R, Scheffer E: Clinical and histologic differentiation between lymphomatoid papulosis and pityriasis lichenoides. J Am Acad Dermatol 1985;13:418-428.

-6 Slater D: The New World Health Organization-European Organization for Research and Treatment of Cancer classification for cutaneous lymphomas: a practical marriage of two giants. Br J Dermatol 2005; 153:874-880.

7 Piamphongsant T: Tetracycline for the treatment of pityriasis lichenoides. Br J Dermatol 1974;91:319322.

-8 Truhan AP, Herbert AA, Esterly NB: Pityriasis lichenoides in children: Therapeutic response to erythromycin. J Am Acad Dermatol 1986;15:66-70.

-9 Simon D, Boudny C, Nievergelt H, Simon HU, Braathen LR: Successful treatment of pityriasis lichenoides with topical tacrolimus. Br J Dermatol 2004;150:1033-1035.

10 Ersoy-Evans S, Hapa AA, Boztepe G, Sahin S, Kölemen F: Narrowband ultraviolet-B phototherapy in pityriasis lichenoides chronica. J Dermatolog Treat 2009;20:109-113. 